\title{
La internación involuntaria en la legislación argentina y brasilera desde la perspectiva de los Derechos Humanos
}

Compulsory Internment in Argentina and Brazil legislation from the perspective of Human Rights

Internação compulsória na legislação argentina e brasileira na perspectiva dos Direitos Humanos

\section{Sofía Puccio'}

Resumen: El artículo tiene como objetivo analizar comparativamente la legislación argentina y brasilera relativa a internación psiquiátrica involuntaria y protección de los derechos humanos de pacientes con sufrimiento mental. Es una investigación descriptivoanalítica, de base documental y legislativa con análisis cualitativo. Tanto en Brasil como en Argentina existen leyes sobre la materia, en la legislación argentina, la Ley $n^{\circ} 26.657$, del 2010, que dispone sobre los derechos de protección a la salud mental de todas las personas y el Decreto Reglamentario $n^{\circ} 603$ del 2013: en la legislación brasilera, la Ley 10.216 del 2001,que dispone sobre los derechos de las personas portadoras de trastornos mentales y la Portería GM n²391 del 2002 que reglamenta el control de las internaciones psiquiátricas involuntarias (IPI) y voluntarias (IPV) y los procedimientos de notificación de la comunicación de las IPI y IPV al Ministerio Público por establecimientos de salud, integrantes y no de SUS. Se establecen los conceptos fundamentales para la comprensión del tema, luego se analizan las influencias de la Convención de Caracas en la legislación de ambos países, para luego presentar el proceso de reforma psiquiátrica. Por fin, con base en un estudio de derecho comparado, se analiza la legislación de los dos países. A pesar de haber crecido Argentina y Brasil en la consolidación de su legislación en salud mental en los últimos años, el poco tiempo que tienen desde su implementación, evidencia que falta avanzar en el control y procedimiento de las internaciones para asegurar que las políticas públicas protejan los Derechos Humanos.

Palabras-claves: Salud Mental, Internación Psiquiátrica Involuntaria, Derechos Humanos, Legislación comparada

Resumo: $O$ artigo tem o objetivo de analisar comparativamente as legislação argentina e brasileira relativas à internação psiquiátrica involuntária e a proteção dos direitos humanos do paciente com sofrimento mental. É uma pesquisa descritivo-analítica, de base documental e legislativa com analise qualitativa. Tanto no Brasil como na Argentina, existem leis sobre a matéria, bem como seus respectivos regulamentos. Na legislação argentina, há a Lei no 26.657, de 2010, que dispõe sobre os direitos a proteção da saúde mental de todas as pessoas, e o Decreto Regulamentar n 603, de 2013. Já na legislação brasileira, há a Lei no 10.216, de 2001, que dispõe sobre a proteção e os direitos das pessoas portadoras de transtornos mentais, e a Portaria GM no 2.391, de 2002 que regulamenta o controle das internações psiquiátricas involuntárias e voluntárias, além dos

\footnotetext{
1 Abogada. Programa de Direito Sanitário (PRODISA) da Fundação Oswaldo Cruz- FIOCRUZ/ DIREB Brasília/DF - Brasil. E-mail: milsofipuccio@gmail.com
} 
procedimentos de notificação da Comunicação das IPI e IPV ao Ministério Público pelos estabelecimentos de saúde, integrantes ou não do SUS. Se estabelecem os conceitos fundamentais para a compreensão do tema, logo se analisam as influências da Convenção de Caracas na nova legislação de ambos os países, para então apresentar o processo da reforma psiquiátrica de ambos os países. Por fim, com base em um estudo de direito comparado, analisa-se a legislação de ambos os países. Apesar dos dois países estarem crescendo na consolidação de sua legislação em saúde mental nos últimos anos, o pouco tempo que há de implantação, evidencia a falta de avanços no controle e procedimento das internações para assegurar que as politicas públicas protejam os Direitos Humanos.

Palavras chaves: Saúde Mental, Internação Psiquiátrica Involuntária, Direitos HumanosLegislação Comparada

Abstract: The article aims to analyse comparatively the Argentine and Brazilian legislations about the involuntary psiquiatric internation and the protection of the human rights of patients with mental suffering. It is a descriptive and analytical investigation, with a documentary and legislative base with qualitative analysis. In both countries there is legislation about this, particularly in Argentina with National Laws 26.657/2010 (rights about people with mental disorders) and Porteria GM no 2391/2002 which regulates the control about involuntary and voluntary psiquiatric's hospitalizations and procedures of notifications to the Public Minister through health's centers, members of and non SUS. There are fundamental concepts to the comprehension of the subject, then the Caracas Convention's influence in both countries is analised and finally it is presented the procedure of psiquiatrics reforms. In the end, based on a study of comparative law, the laws of the two countries are analyzed. Although Argentina and Brazil have been growing up in mental health legislation's consolidation in last years, they have had little time since their implementation, which show us that they have a long way to take a better control and procedures in hospitalizations which ensure public policies to protect human rights.

Keywords: Mental Health, Involuntary Psiquiatric Hospitalization, Human Rights, Comparative Law.

\section{Introducción}

En las décadas de 1970 a 1990, la mayoría de los países llevaron a cabo reformas psiquiátricas, con variantes legislativas que pueden ser comparadas. Este es el caso de Brasil y de Argentina que realizaron sus reformas en periodos bastantes próximos, ya que ambos poseen sistemas de salud universales, y a su vez poseen problemas en el ámbito de la salud mental que se aproximan mucho.

En este artículo fueron analizadas comparativamente, las normas jurídicas argentinas y brasileras que tratan sobre la salud mental, con respecto a la internación psiquiátrica involuntaria y a la protección de los derechos humanos del paciente con padecimiento mental. 
En primer lugar se establecieron los conceptos fundamentales para la comprensión del tema, posteriormente se analizaron las influencias de la Convención de Caracas en la nueva legislación de ambos países, para entonces presentar el proceso de reforma psiquiátrica ocurrida en Argentina y Brasil. Por último con base en un estudio de derecho comparado se analizo la legislación de Argentina (Ley 26.557/2012 y el Decreto Reglamentario 603/13) y la legislación de Brasil (Ley 10.126/2001 y la Portaría 2391/2002) (1) (2) (3) (4).

El derecho comparado, según Duarte (5), es la comparación de ordenamientos jurídicos diferentes. Implica la yuxtaposición de los resultados del estudio y el registro de sus semejanzas y diferencias.

Destaca Sacco (6) "que a comparação não comporta necessariamente uma valoração, positiva ou negativa, favorável ou crítica, das outras instituições". ${ }^{2}$

De acuerdo con Giovarino (7), las internaciones involuntarias privan a las personas de su libertad ambulatoria es por eso que deben ser medidas excepcionales, ya que la libertad ambulatoria es un derecho de suma importancia que debe ser protegido por todos los Estados.

Según la Ley de Argentina 26.657/2010 (1), de la Protección de la Salud Mental, en el artículo 20:

La internación involuntaria de una persona debe concebirse como recurso terapéutico excepcional en caso de que no sean posibles los abordajes ambulatorios, y sólo podrá realizarse cuando a criterio del equipo de salud mediare situación de riesgo cierto e inminente para sí o para terceros. [...].

Según la ley de Brasil 10.216/2001, en su artículo 4ํㅜㄹ con respecto a las internaciones en cualquiera de sus modalidades, solo será indicada cuando los recursos extra hospitalarios se muestren insuficientes y el tratamiento se realizara con la finalidad permanente de la reinserción social del paciente en su médio (3).

Con la definición clara de esos parámetros las leyes de ambos países - Argentina y Brasil- impiden que la internación involuntaria sea determinada de forma arbitraria o sin observación de los aspectos importantes para el bienestar del paciente y para la protección de sus derechos humanos.

2 "Que la comparación no comporta necesariamente una valoración positiva o negativa favorable o critica, de las otras instituciones (Traducción libre de la autora). 
Se entiende por Derechos Humanos, según el preámbulo de la Declaración Universal de los Derechos Humanos de las Naciones Unidas, los derechos inherentes a todos los seres humanos, sin distinción alguna de nacionalidad, lugar de residencia, sexo, origen nacional o etnia, color, religión, lengua o cualquier otra condición. Todos tienen los mismos derechos humanos, sin discriminación alguna. De acuerdo con su artículo 1ㅇ․ " Todos los seres humanos nacen libres e iguales en dignidad y derechos y, dotados como están de razón y conciencia, deben comportarse fraternalmente los unos con los otros".

\section{Metodología}

Se trató de una investigación descriptivo-analítica, de base documental y legislativa con análisis cualitativo.

De acuerdo con Marconi y Lakatos (8) la investigación cualitativa analiza en profundidad los aspectos más importantes, asegurando así, un análisis detallado sobre las investigaciones, tendencias etc.

La investigación descriptiva según Gil (9), pretende describir los estudios de fenómenos para brindar un mayor conocimiento sobre los asuntos estudiados. La investigación analítica complementa el estudio descriptivo a través de su profundización. Pues, además de registrar y analizar los fenómenos busca identificar las causas a través de la interpretación que posibilitan los métodos cualitativos (10).

De acuerdo con Serrano (11):

A primeira grande utilidade das análises de direito comparado é a possibilidade de indicar as normas jurídicas afins nas legislações nacionais e estrangeiras, com o objetivo de confrontá-las para determinar as analogias e diferenças existentes entre sistemas e institutos, bem como avaliar o desenvolvimento e aproximação das legislações ou instituições jurídicas de diversos países. ${ }^{3}$

Las bases normativas de Brasil sobre el tema de las internaciones involuntarias fueron obtenidas de las bases de datos de la red de información legislativa y jurídica

\footnotetext{
${ }^{3}$ La primera gran utilidad del análisis del derecho comparado es la posibilidad de indicar las normas jurídicas afines en la legislación nacional y extranjera, con el objetivo de confrontarlas para determinar las analogías y diferencias existentes entre sistemas e institutos, como también evaluar el desenvolvimiento y aproximación de las legislaciones o instituciones jurídicas de diversos países. (traducción libre de la autora).-
} 
disponible en el sitio www.lexml.gov.br; las bases normativas de la Argentina en el portal de www.infoleg.gov.ar.

La revisión bibliográfica sobre los temas de la reforma psiquiátrica, la Declaración de Caracas y los derechos humanos e internaciones involuntarias, se utilizo la base de datos de $\underline{\text { Scielo, }}$ Lilacs, entre otros. Para la investigación se utilizaron los siguientes descriptores: salud mental e internación involuntaria.

\section{Resultados y discusión}

En la legislación Argentina se encontraron diez normativas infra legales en relación a la materia de Salud Mental: internación involuntaria de las cuales ocho son resoluciones y dos decretos. Después de la realización de un análisis ocho fueron descartadas porque no abarcaban directamente el tema de la internación involuntaria, pues la temática traspasaba el objeto de investigación.

En Brasil se encontraron ocho registros de normativas federales en el periodo de 1990-2014. Se observo que siete de los registros encontrados debían ser descartados por no decir nada directamente de las internaciones involuntarias, considerando el contenido de sus enmiendas.

En la legislación Argentina fue identificada la ley n²6.657/2010, que dispone sobre los derechos y la protección de la salud mental de todas las personas y el decreto reglamentario no 603/2013. En la legislación de Brasil, se analizo la ley ํㅜ 10.216/2001, que dispone sobre la protección de los derechos de las personas portadoras de trastornos mentales, además de la Portería GM № 2.391, del 2002, que reglamenta el control de las internaciones psiquiátricas involuntarias (IPI) y voluntarias (IPV) de acuerdo con lo dispuesto en la ley 10.216 del 6 de abril del 2002 y los procedimientos de notificación de la Comunicación de las IPI e IPV al Ministerio Público por los establecimientos de salud, integrantes o no del SUS. 


\section{La nueva perspectiva de la Salud Mental después de la Declaración de Caracas}

La declaración de Caracas - fue adoptada en 1990 y apoyada por 200 representantes de 11 países de América Latina- marco un hecho importante en el desenvolvimiento de los sistemas de salud mental en el continente americano.

Entre los principales objetivos de la Declaración de Caracas, encontramos: la reestructuración de la asistencia psiquiátrica (ligada a los cuidados de salud primaria), la promoción de cuidados alternativos y garantizar a través de la legislación el respeto por los derechos humanos y civiles del enfermo.

Una de las estrategias que deriva de la Declaración de Caracas fue la actualización de las legislaciones nacionales, para asegurar el respeto a los derechos humanos de las personas con padecimientos mentales y a sus familias. Tanto Brasil como Argentina tienen actualmente políticas nacionales de salud mental. La aprobación de amas políticas fue posterior a la Declaración de Caracas. Es importante destacar que en ambos países, el resurgimiento de los gobiernos democráticos traja aparejado las reivindicaciones de los derechos humanos, que se amplió hasta el área de la salud mental "Renació así una toma de conciencia sobre los derechos humanos de toda la población y en particular de los derechos de los enfermos mentales" (12).

\section{El proceso de la reforma psiquiatrica en Brasil}

Según Amarante (13) "o processo da reforma [psiquiátrica] no Brasil começou no final da década de 1970, no contexto da redemocratização nacional". ${ }^{4}$

De acuerdo con Maciel (14):

A reforma psiquiátrica surgiu, então, no sentido de questionar a instituição asilar e a prática médica, e humanizar a assistência, fazendo com que houvesse ênfase na reabilitação ativa em detrimento da custódia e da segregação. ${ }^{5}$

Amarante (13) dice que, hasta el final de la década del 80, la asistencia a los portadores de trastornos mentales se caracterizó casi exclusivamente por la hospitalización, con los inconvenientes de la cronificación, exclusión social y costos elevados. En 1988, fue promulgada la nueva Constitución Federal que tiene un capitulo

\footnotetext{
4 "El proceso de la reforma psiquiátrica en Brasil comenzó al final de la década de 1970, en el contexto de la redemocratización nacional" (Traducción libre de la autora)

5 "La reforma psiquiátrica surgió, entonces, con el sentido de cuestionar la institución asilar y la practica medica, humanizar la asistencia, haciendo énfasis en la rehabilitación activa en detrimento de la custodio de segregación. (Traducción libre de la autora).
} 
especifica dedicada a la salud, que paso a ser considerada derecho de todos y deber del Estado. Esto fue una victoria del movimiento de la reforma sanitaria, en el cual está incluido el movimiento de la reforma psiquiátrica.

En estos años acontecieron en distintas ciudades de Brasil distintos hechos que contribuyeron para que la Reforma Psiquiátrica ocurriera. Entre esos hechos se destaca lo ocurrido en Santos en el año 1989, que se tornó muy importante por su enorme repercusión. Esto posibilitó el aparecimiento en octubre de aquel mismo año del proyecto de Ley no3.657 (PL 3.657/1989), de autoría del Diputado Paulo Delgado, que proponía la extinción progresiva de los manicomios y su sustitución por otros servicios de salud mental. Lo importante es que este proyecto dio origen a un sustituto que posibilitó muchas innovaciones en el campo del modelo asistencial de los derechos humanos.

O Projeto de Lei foi transformado na Lei oㅜ 10.216, de 6 de abril de 2001, atualmente em vigor, que dispõe sobre a extinção progressiva dos manicômios e sua substituição por novas modalidades de atendimento, como Hospitais-Dia (HDs), Centro de Atenção Psicossocial (CAPS) e Lares Protegidos. [...] Mudou-se o modelo de atenção mental por serviços substitutivos ao hospital psiquiátrico. (14). ${ }^{6}$

La política nacional de salud mental brasilera asumió un carácter innovador. Dentro de los aportes más importantes, se pueden destacar la participación y el control social, propios del modelo de SUS, con la utilización de los consejos y las conferencias de salud mental que son los canales democráticos.

\section{El proceso de reforma psiquiátrica en Argentina}

Durante la década de 1960 se inicio la revisión de los objetivos de los hospitales siquiátricos, conducida por los médicos psiquiatras Pichón Rivieré, José Bleger, Mauricio Goldenberg e Valentín Beneblit, que lograron incorporar practicas modernas con el sentido de encontrar nuevos modos de comprender y organizar los cuidados de las personas con padecimientos mentales. Para alcanzar el objetivo de cerrar las instituciones psiquiatricas asilares, tuvieron que trabajar sobre dos premisas: crear un sistema alternativo y dar una solución para las personas que estaban institucionalizadas (15).

6 "El proyecto de Ley fue transformado en la Ley 10.216, del 6 de abril de 2001, actualmente en vigor, que dispone sobre la extinción progresiva de los manicomios y su sustitución por nuevas modalidades de atención, como hospitales de día, Centro de Atención Psicosocial y lugares protegidos [...] Se paso del modelo de atención mental a los servicios sustitutivos de hospital psiquiátrico. (Traducción libre de la autora). 
Según Ottaviano (15) es importante tener en cuenta que el país pasó por conflictos políticos y sociales en las décadas de 1970 a 1980. Fue en el año 1993 que Emiliano Galende, especialista en salud mental, organizó una política en este campo de Salud Mental, constituida en redes asistenciales, que integraban las familias y los grupos primarios en los tratamientos.

En el año 2010, fue promulgada la Ley Nacional de Salud Mental, a partir de ese momento el país comenzó a recorrer un nuevo camino, como el cierre de los hospitales psiquiátricos, la integración de los pacientes a la comunidad y - lo más importante- el respeto por los derechos humanos de las personas con padecimientos mentales, teniendo en cuenta la definición de salud mental de la nueva ley.

De ese modo se dio comienzo a un proceso de desconstrucción del manicomio. Esa decisión contó con el apoyo de la Organización Panamericana de Salud (OPAS), de profesionales de Salud Mental y de las familias de los pacientes.

\section{Internación Compulsoria: primera aproximación}

Conforme los "Principios para la Protección de los Enfermos Mentales y el Mejoramiento de la Atención de la Salud Mental" adoptados por la Asamblea de las Naciones Unidas, en su Resolución №46/119, de 17 de diciembre de 1991, una persona solo puede ingresar involuntariamente a una institución de salud mental como paciente, cuando sea portadora de una enfermedad mental grave, como consecuencia de la cual su capacidad de juicio se vea afectada o que el hecho de que no sea admitida o retenida en una institución psiquiátrica pueda traer aparejado un gran daño a su condición. Los enfermos mentales son sujetos especialmente vulnerables, que muchas veces enfrentan situaciones de discriminación y marginalización, incrementándose la posibilidad de que sean violados sus derechos.

\section{Las internaciones compulsorias en la legislación de Argentina y Brasil}

En el sistema legal argentino, la previsión legal sobre las internaciones involuntarias esta prevista en la Ley $\mathrm{n}^{\circ} \mathbf{2 6 . 6 5 7}$, de diciembre del 2010, y en el Decreto Reglamentario $\mathrm{n}^{\circ}$ 603, de 2013. En la legislación brasilera está prevista en la Ley no 10.216, de abril de 2001, y en la Portaría GM n².391, de diciembre de 2002. 
Cuadro I - Normas jurídicas sobre Salud Mental e internaciones compulsorias en Argentina y Brasil.

\begin{tabular}{|c|c|c|c|}
\hline País & Especie & $\begin{array}{c}\text { Fecha de vigencia y } \\
\text { origen }\end{array}$ & Enmienda \\
\hline Argentina & Ley Federal № 26.657 & $\begin{array}{l}02 / 12 / 10 \text { Congreso } \\
\text { Nacional }\end{array}$ & $\begin{array}{l}\text { Tiene por objeto asegurar el } \\
\text { derecho y la protección de la salud } \\
\text { mental de todas las personas y el } \\
\text { pleno goce de los derechos } \\
\text { humanos de aquellas con } \\
\text { padecimiento mental que se } \\
\text { encuentran en el territorio nacional, } \\
\text { reconocidos en los instrumentos } \\
\text { internacionales de derechos } \\
\text { humanos con jerarquía } \\
\text { constitucional. }\end{array}$ \\
\hline Argentina & Decreto no 603/2013 & $\begin{array}{l}28 / 05 / 2013 \\
\text { Poder Ejecutivo } \\
\text { Federal }\end{array}$ & Reglamenta a Ley Nº 26.657 \\
\hline Brasil & $\begin{array}{l}\text { Ley Federal n } 10.216 \text {, de } \\
2001 .\end{array}$ & $\begin{array}{l}\text { 06/04/2001 Congreso } \\
\text { Nacional }\end{array}$ & $\begin{array}{l}\text { Dispone sobre la protección y } \\
\text { derechos de las personas } \\
\text { portadoras de trastornos mentales } \\
\text { y redirecciona el modelo asistencial } \\
\text { de la salud mental. }\end{array}$ \\
\hline Brasil & $\begin{array}{l}\text { Porteria GM no 2.391, de } \\
2001 .\end{array}$ & $\begin{array}{l}\text { 26/12/2002 Ministerio } \\
\text { de Salud }\end{array}$ & $\begin{array}{l}\text { Reglamenta el control de las } \\
\text { internaciones psiquiátricas } \\
\text { involuntarias (IPI) de acuerdo con } \\
\text { lo dispuesto en la Ley } 10.216 \text {, del } 6 \\
\text { de abril de } 2002 \text {, de la } \\
\text { comunicación de las IPI e IPV al } \\
\text { Ministerio Publico por los } \\
\text { establecimientos de salud, } \\
\text { integrantes o no de SUS. }\end{array}$ \\
\hline
\end{tabular}

Fuente: Infoleg (Argentina) y Portal de la Legislación de Gobierno Federal (Brasil)

El plan de acción sobre la Salud Mental 2013-2020 de la Organización Mundial de la

Salud define la legislación sobre la salud mental como:

Son las disposiciones sobre el particular incorporadas en otras leyes [...]pueden abarcar una serie de cuestiones tales como el acceso a la asistencia y los servicios de salud mental, la calidad de dicha asistencia, el ingreso en establecimientos para enfermos mentales, el consentimiento para ser tratado, protección contra el trato cruel, deshumano y degradante, la protección contra la discriminación, goce de una variedad de derechos civiles, culturales, económicos, políticos y sociales; y la instauración de mecanismos legales para promover y proteger los derechos humanos [...]. (16) 
Cuadro II: Principales puntos de la legislación Argentina y Brasilera.

\begin{tabular}{|c|c|c|}
\hline & Legislación Argentina & Legislación Brasileira \\
\hline $\begin{array}{l}\text { Concepto de Salud } \\
\text { Mental }\end{array}$ & $\begin{array}{l}\text { Proceso determinado por } \\
\text { componentes históricos, } \\
\text { socioeconómicos, culturales, } \\
\text { biológicos y psicológicos cuya } \\
\text { preservación y mejoramiento, implican } \\
\text { una dinámica de construcción social } \\
\text { vinculada a la concretización de los } \\
\text { derechos humanos y sociales de toda } \\
\text { persona. }\end{array}$ & No Define \\
\hline $\begin{array}{l}\text { Derechos Humanos } \\
\text { (Tratados) }\end{array}$ & $\begin{array}{l}\text { Pleno goce de los DDHH de aquellas } \\
\text { personas con padecimiento mental en } \\
\text { el territorio nacional. Reconocidos en } \\
\text { instrumentos internacionales. Art. } 75 \\
\text { inc. } 22 \mathrm{CN} \text {. }\end{array}$ & $\begin{array}{l}\text { Los derechos y la protección de las } \\
\text { personas con trastornos mentales, } \\
\text { de que trata esta ley, son } \\
\text { asegurados sin ninguna forma de } \\
\text { discriminación en cuanto a raza, } \\
\text { color, sexo, orientación sexual, } \\
\text { religión, opción política, nacionalidad, } \\
\text { edad, familia, recursos económicos y } \\
\text { el grado de gravedad o tiempo de } \\
\text { evolución de su trastorno, o cualquier } \\
\text { otra. }\end{array}$ \\
\hline $\begin{array}{l}\text { Instrumentos de } \\
\text { orientación para la } \\
\text { planificación de las } \\
\text { políticas públicas. }\end{array}$ & $\begin{array}{l}\text { Principios sobre la Protección } \\
\text { de enfermos mentales y para el } \\
\text { mejoramiento de la salud mental, de la } \\
\text { ONU, de } 17 \text { de diciembre de } 1991^{7} ; \\
\text { - } \quad \text { Declaración de Caracas; } \\
\text { - } \quad \text { Principios de Brasilia }\end{array}$ & $\begin{array}{l}\text { - Principios sobre la } \\
\text { Protección de enfermos mentales y } \\
\text { para el mejoramiento de la salud } \\
\text { mental, de la ONU, de } 17 \text { de } \\
\text { diciembre de 1991; } \\
\text { - } \quad \text { Resoluciones del Seminario } \\
\text { "Direito à Saúde Mental" -2001. } \\
\text { - Consultas realizadas por el } \\
\text { Ministerio de Salud; } \\
\text { - Las conclusiones de la III } \\
\text { Conferencia Nacional de Salud } \\
\text { Mental, } \\
\text { - Las consultas realizadas por } \\
\text { el Ministerio de Salud junto a los } \\
\text { municipios y estados de SUS, en el } \\
\text { área de Salud Mental. }\end{array}$ \\
\hline Concepto de internación & $\begin{array}{l}\text { Es considerada como un recurso } \\
\text { terapéutico de carácter restrictivo, y } \\
\text { solo puede llevarse a cabo cuando } \\
\text { aporte mayores beneficios } \\
\text { terapéuticos que el resto de las } \\
\text { intervenciones realizables en su } \\
\text { entorno familiar, comunitario o social, } \\
\text { salvo en aquellas excepciones que por } \\
\text { razones terapéuticas debidamente } \\
\text { fundadas establezca el equipo de } \\
\text { salud interviniente. }\end{array}$ & $\begin{array}{l}\text { La internación psiquiátrica solamente } \\
\text { deberá ocurrir después de todas las } \\
\text { tentativas de utilización de las demás } \\
\text { opciones terapéuticas y agotados } \\
\text { todos los recursos extra-hospitalarios } \\
\text { disponibles en la red asistencial, con } \\
\text { la menor duración temporal posible. }\end{array}$ \\
\hline
\end{tabular}

7 ONU. Asamblea General de las Naciones Unidas en su Resolución № 46/119 del 17/12/1991. Principio 16 inc. 1. [on line] Disponível em: http://direitoshumanos.gddc.pt/3 7/llIPAG3 7 6.htm. [data de consulta: set. 2014]. 
Cad. Ibero-Amer. Dir. Sanit., Brasília, v.4, n.4, out./dez. 2015 ISSN 2358-1824

\begin{tabular}{|c|c|c|}
\hline Clases de Internación & $\begin{array}{ll}- & \text { Internación Voluntaria } \\
\text { - } & \text { Internación Involuntaria }\end{array}$ & $\begin{array}{l}\text { • Internación Psiquiátrica } \\
\text { Involuntaria (IPI); } \\
\text { • Internación Psiquiátrica } \\
\text { Voluntaria (IPV), } \\
\text { • Internación Psiquiátrica } \\
\text { Voluntaria que se torna Involuntaria } \\
(\text { IPVI), (agregada por la Portería } \\
2391 / 2002) \\
\text { Compulsoria (IPC). }\end{array}$ \\
\hline $\begin{array}{l}\text { Concepto de internación } \\
\text { Involuntaria y } \\
\text { Compulsoria. }\end{array}$ & $\begin{array}{l}\text { La internación involuntaria: es un } \\
\text { recurso terapéutico excepcional en } \\
\text { caso de que no sean posibles los } \\
\text { abordajes ambulatorios, y solo podrá } \\
\text { realizarse cuando a criterio del equipo } \\
\text { de salud mediare situación de riesgo } \\
\text { cierto e inminente para sí o para } \\
\text { terceros. } \\
\text { No tiene internación compulsoria. }\end{array}$ & $\begin{array}{l}\text { Internación involuntaria: aquella que } \\
\text { se da sin el consentimiento del } \\
\text { usuario y a pedido de un tercero. } \\
\text { Internación Compulsoria: aquella } \\
\text { determinada por la Justicia. }\end{array}$ \\
\hline $\begin{array}{l}\text { Características del } \\
\text { procedimiento de } \\
\text { internación involuntaria/ } \\
\text { Compulsoria }\end{array}$ & $\begin{array}{l}\text { Debe estar debidamente fundada. } \\
\text { Notificarse obligatoriamente en el } \\
\text { plazo de } 10 \text { horas al juez competente } \\
\text { y al órgano de revisión. } \\
\text { La persona internada tiene derecho a } \\
\text { designar un abogado, sino el Estado } \\
\text { debe proporcionarlo. }\end{array}$ & $\begin{array}{l}\text { Es necesario un laudo } \\
\text { circunstanciado que enumere sus } \\
\text { motivos. } \\
\text { En el plazo de } 72 \mathrm{hs} \text { debe ser } \\
\text { comunicado al MPE. } \\
\text { No está reglamentada la internación } \\
\text { compulsoria. }\end{array}$ \\
\hline $\begin{array}{l}\text { Control de la internación } \\
\text { involuntaria/ } \\
\text { Compulsoria }\end{array}$ & $\begin{array}{l}\text { El juez debe solicitar informes cada } \\
\text { treinta días para evaluar si persisten } \\
\text { las razones para que persista esa } \\
\text { medida y podrá pedir en cualquier } \\
\text { momento su externación. } \\
\text { A los noventa días, luego del tercer } \\
\text { informe el juez debe pedir al órgano de } \\
\text { revisión que designe un equipo } \\
\text { interdisciplinar para obtener una nueva } \\
\text { evaluación. }\end{array}$ & $\begin{array}{l}\text { MPE podrá solicitar informaciones } \\
\text { complementarias al autor del laudo y } \\
\text { a la dirección del establecimiento, } \\
\text { realizar entrevistas con los } \\
\text { internados, sus familiares, autorizar a } \\
\text { otros especialistas para examinar al } \\
\text { internado. } \\
\text { La Comisión Revisora efectuara } \\
\text { hasta el séptimo día de la internación } \\
\text { la revisión de cada IPI, emitiendo un } \\
\text { laudo de confirmación o suspensión } \\
\text { del régimen de tratamiento adoptado. } \\
\text { El director del establecimiento } \\
\text { enviara mensualmente un informe al } \\
\text { gestor estadual de SUS. }\end{array}$ \\
\hline $\begin{array}{l}\text { Órganos y personas que } \\
\text { intervienen }\end{array}$ & $\begin{array}{ll}\text { - } & \text { Juez } \\
\text { - } & \text { Órgano de revisión } \\
\text { - } & \text { Equipo interdisciplinar }\end{array}$ & $\begin{array}{ll}- & \text { MPE } \\
-\quad & \text { Comisión Revisora } \\
\text { - } & \text { Director del establecimiento. }\end{array}$ \\
\hline
\end{tabular}

Fuente: Infoleg (Argentina) y portal de la Legislación del Gobierno Federal (Brasil)

\section{Análisis de la Legislación Argentina}

La ley 26.657/2010 tiene por objeto asegurar el derecho a la protección de la salud mental de todas las personas, además del pleno goce de los derechos humanos de 
aquellas con padecimientos mentales, que se encuentren en el territorio nacional reconocido en instrumentos internacionales con jerarquía constitucional, en el articulo 75 inc. 22 de la Constitución Nacional. El decreto reglamentario 603/2013 menciona alguno de esos derechos; como el derecho de toda persona a la mejor atención disponible en salud mental, al trato digno, respetuoso y equitativo, establece la responsabilidad del Estado en garantizarles el derecho a recibir un trato personalizado en un ambiente adecuado con las modalidades de atención basada en las comunidades, entendiendo la internación como una medida restrictiva que solo debe ser aplicada como último recurso terapéutico. De acuerdo con Sainz et al (17):

Es necesario subrayar la importancia y el avance que propone la Ley de Salud Mental en lo que respecta a las políticas del Estado, ya que apunta a restablecer los derechos vulnerados de aquellos que padecen trastornos mentales.

Según Escudero (18) con respecto al Decreto 603/2013:

La vigencia del Decreto $603 / 13$ es una etapa importante por cuanto refuerza y complementa los cambios introducidos por la norma en el sentido de implementar un modelo de atención que esté basado en el respeto de la persona en toda su integridad y a sus derechos humanos, favorece su inclusión como participes activos -en la medida de sus capacidades- del entramado social que los circunda.

Se consideran instrumentos de orientación para la planificación de las políticas públicas, los Principios de las Naciones Unidas para la protección de los enfermos mentales y para el mejoramiento de la atención a la salud mental, la Declaración de Caracas de la Organización Panamericana de Salud y de la Organización Mundial de la Salud (OPAS/OMS), para la reestructuración de la atención psiquiátrica dentro de los sistemas locales de salud, y los Principios Rectores de Brasilia, para el desenvolvimiento de la atención en salud mental de las Américas.

En su artículo 3ํㅗ la ley 26.657 define la salud mental como:

En el marco de la presente ley se reconoce a la salud mental como un proceso determinado por componentes históricos, socioeconómicos, culturales, biológicos y psicológicos cuya preservación y mejoramiento implica una dinámica de construcción social vinculada a la concreción de los derechos humanos y sociales de toda persona [...] 

mental como:

En el artículo $1^{\circ}$ del Decreto 603/13, se define lo que se entiende por padecimiento

Entiéndase por padecimiento mental a todo tipo de sufrimiento psíquico de las personas y/o grupos humanos, vinculables a distintos tipos de crisis previsibles o imprevistas, así como a situaciones más prolongadas de padecimientos, incluyendo trastornos $y / 0$ enfermedades, como proceso complejo determinado por múltiples, componentes, de conformidad con lo establecido en el artículo $3^{\circ}$ de la Ley № 26.657. (2)

En su articulo7ํ la ley 26.657 enumera los derechos de las personas con padecimiento mental, entre ellos podemos destacar los siguientes: derecho a recibir atención sanitaria y social, integral y humanizada, a partir del acceso gratuito, igualitario y equitativo a las prestaciones e insumos necesarios, derecho a recibir tratamiento y ser tratado con la alternativa terapéutica más conveniente, que menos restrinja sus derechos y libertades, derecho a que en el caso de internación involuntaria o voluntaria prolongada, las condiciones de las mismas sean supervisadas periódicamente por el Organismo de Revisión; derecho a no ser identificado ni discriminado por un padecimiento mental que no sea considerado un estado inmodificable, entre otros. El Decreto Reglamentario 603/2013 aclara que los derechos enumerados en el artículo $7^{\circ}$ son meramente enunciativos.

En el capítulo VII de la ley $26.657 / 2010$ se abordan temas de las internaciones, específicamente en su artículo 14ํmenciona:

La internación es considerada como un recurso terapéutico de carácter restrictivo, y sólo puede llevarse a cabo cuando aporte mayores beneficios terapéuticos que el resto de las intervenciones realizables en su entorno familiar, comunitario o social. Debe promoverse el mantenimiento de vínculos, contactos y comunicación social de las personas internadas con sus familiares, allegados y con el entorno laboral y social, salvo aquellas excepciones que por razones terapéuticas debidamente fundadas establezca el equipo de salud interviniente.

Según el Decreto las restricciones deben ser excepcionales, debidamente fundadas por el equipo interdisciplinar y deberán ser informadas al juez competente.

La internación debe ser lo más breve posible, en función de los criterios terapéuticos interdisciplinares. Conforme Giovarino (7)

La internación se puede concebir válidamente como una medida cautelar que cabe no solo para el demente sino también para quienes sin serlo se encuentran en situación de vulnerabilidad por su déficit o adicción. 
Según la legislación Argentina las internaciones pueden ser divididas en internación voluntaria o internación involuntaria. La internación involuntaria es definida en su artículo $20^{\circ}$ :

La internación involuntaria de una persona debe concebirse como recurso terapéutico excepcional en caso de que no sean posibles los abordajes ambulatorios, y sólo podrá realizarse cuando a criterio del equipo de salud mediare situación de riesgo cierto e inminente para sí o para terceros. Para que proceda la internación involuntaria, además de los requisitos comunes a toda internación debe constar:

a) Dictamen profesional del servicio asistencial que realice la internación. Se debe determinar la situación de riesgo cierto e inminente a que hace referencia el primer párrafo de este artículo, con la firma de dos profesionales de diferentes disciplinas, que no tengan relación de parentesco, amistad o vínculos económicos con la persona, uno de los cuales deberá ser psicólogo o médico psiquiatra;

b) Ausencia de otra alternativa eficaz para su tratamiento;

c) Informe acerca de las instancias previas implementadas si las hubiera

El proceso para que proceda la internación involuntaria en Argentina tiene los siguientes aspectos importantes mencionados en el artículo $21^{\circ}$ de la ley 26.657/2010:

La internación involuntaria debidamente fundada debe notificarse obligatoriamente en un plazo de DIEZ (10) horas al juez competente y al órgano de revisión, debiendo agregarse a las CUARENTA Y OCHO (48) horas como máximo todas las constancias previstas en el artículo 20. El juez en un plazo máximo de TRES (3) días corridos de notificado debe:

a) Autorizar, si evalúa que están dadas las causales previstas por esta ley;

b) Requerir informes ampliatorios de los profesionales tratantes o indicar peritajes externos, siempre que no perjudiquen la evolución del tratamiento, tendientes a evaluar si existen los supuestos necesarios que justifiquen la medida extrema de la internación involuntaria y/o;

c) Denegar, en caso de evaluar que no existen los supuestos necesarios para la medida de internación involuntaria, en cuyo caso debe asegurar la externación de forma inmediata.

El juez sólo puede ordenar por sí mismo una internación involuntaria cuando, cumplidos los requisitos establecidos en el artículo 20, el servicio de salud responsable de la cobertura se negase a realizarla

Cuando sucede una internación, el juez debe solicitar informes cada treinta (30) días a fin de evaluar si persisten las razones para que continúe la medida pudiendo en cualquier momento pedir su alta. A los noventa (90) días, luego del tercer informe, el juez debe pedir 
al organo de revisión que designe un equipo interdisciplinar, para obtener una nueva evaluación. En caso de que hubiera diferencia de criterios, el juez escogerá el que menos restrinja la libertad de la persona internada.

La Ley 26.657/2010 en su artículo 13 define al equipo interdisciplinar:

Los profesionales con título de grado están en igualdad de condiciones para ocupar los cargos de conducción y gestión de los servicios y las instituciones, debiendo valorarse su idoneidad para el cargo y su capacidad para integrar los diferentes saberes que atraviesan el campo de la salud mental. Todos los trabajadores integrantes de los equipos asistenciales tienen derecho a la capacitación permanente y a la protección de su salud integral, para lo cual se deben desarrollar políticas específicas.

De acuerdo con el artículo $27^{\circ}$ está prohibida la creación de nuevos manicomios neuropsiquiatricos o instituciones monovalentes y los ya existentes deben adaptar sus objetivos a los principios de la nueva legislación. De acuerdo con el decreto 603/2013, la sustitución definitiva de los establecimientos deberá ser cumplida hasta el año 2020, de acuerdo con el Consenso de Panamá, adoptado por la Conferencia Regional de Salud Mental convocada por la OPAS/OMS, en el año 2010, en la ciudad de Panamá.

Según el artículo 28으 las internaciones deben ser realizadas en los hospitales generales. La negativa de atención a estos pacientes, es considerada discriminatoria.

Por último, en el articulo 29ำ trata sobre los derechos humanos, específicamente:

A los efectos de garantizar los derechos humanos de las personas en su relación con los servicios de salud mental, los integrantes, profesionales y no profesionales del equipo de salud son responsables de informar al órgano de revisión creado por la presente ley y al juez competente, sobre cualquier sospecha de irregularidad que implicara un trato indigno o inhumano a personas bajo tratamiento o limitación indebida de su autonomía.

\section{Análisis de la Legislación de Brasil}

La Ley 10.216/2001 dispone sobre la protección de los derechos de las personas portadoras de trastornos mentales y redirecciona el modelo asistencial en salud mental y la Portería 2391/GM, de 2002, reglamenta el control de las internaciones involuntarias (IPI) y voluntarias (IPV), de acuerdo con lo dispuesta en la Ley $10.216 / 2001$ y los procedimientos 
de notificación de la Comunicación de las IPI y IPV al Ministerio Publico por los establecimientos de salud, integrantes o no de SUS.

En el artículo $1^{\circ}$ de la Ley 10.216/2001:

Os direitos e a proteção das pessoas acometidas de transtorno mental, de que trata esta Lei, são assegurados sem qualquer forma de discriminação quanto à raça, cor, sexo, orientação sexual, religião, opção política, nacionalidade, idade, família, recursos econômicos e ao grau de gravidade ou tempo de evolução de seu transtorno, ou qualquer outra. ${ }^{8}$

Con respecto a las internaciones en cualquiera de sus modalidades, solo será indicada cuando los recursos extra hospitalarios fueran insuficientes y el tratamiento tenga como finalidad permanente la reinserción social del paciente en su medio, según el artículo $4^{\circ}$ da Ley $10.216 / 2001$.

Este artículo traduce la intención legislativa, tiene el sentido de limitar las internaciones, basado en un movimiento de la psiquiatría que propone la interacción del enfermo en la sociedad como parte del tratamiento. Por lo cual su segregación en el medio social, profesional y familiar, solamente es admitida en situaciones extremas (19).

El artículo 6으 de la ley dispone que la internación psiquiátrica solamente será realizada mediante informe médico circunstanciado que determine sus motivos. Teniendo en cuenta este artículo, encontramos los siguientes tipos de internación: I- Internación voluntaria, se da con el consentimiento del usuario; II- internación involuntaria se da sin el consentimiento del usuario y por último, III- internación compulsoria determinada por la justicia.

En el artículo $3^{\circ}$ de la Portería $2.391 / 2002$ en cambio se establecen cuatro modalidades de internación: internación psiquiátrica involuntaria (IPI), internación psiquiátrica voluntaria (IPV), internación psiquiátrica que se torna involuntaria (IPIV) cuando el paciente internado expresa su discordancia con la mantención de su internación, y la internación psiquiátrica compulsoria (IPC).

\footnotetext{
8 Los derechos y la protección de las personas que padecen trastorno mentales, de que trata esta ley, son asegurados sin cualquier forma de discriminación en cuanto a raza, color, sexo, orientación sexual, religión, opción política, nacionalidad, edad, familia, recursos económicos y el grado de gravedad o tiempo de evolución de su trastorno o cualquier otra. (Traducción libre de la autora)
} 
De acuerdo con De Lima (19): "No embate entre cidadão e Estado, por vezes, é justificável, por razões de segurança e saúde pública, o sacrifício da autonomia individual. São os casos de internação compulsória [...]"9

El artículo 8o de la ley 10.216/2001 dispone:

A internação voluntária ou involuntária somente será autorizada por médico devidamente registrado no Conselho Regional de Medicina - CRM do Estado onde se localize o estabelecimento. $\S 10$ A internação psiquiátrica involuntária deverá, no prazo de setenta e duas horas, ser comunicada ao Ministério Público Estadual pelo responsável técnico do estabelecimento no qual tenha ocorrido, devendo esse mesmo procedimento ser adotado quando da respectiva alta.

§ 20 O término da internação involuntária dar-se-á por solicitação escrita do familiar, ou responsável legal, ou quando estabelecido pelo especialista responsável pelo tratamento. ${ }^{10}$

Según Amarante (13), este es un punto importante de la ley, que establece la obligatoriedad del responsable técnico del establecimiento de comunicar al Ministerio Público Estatal la internación psiquiátrica involuntaria. De esa forma esta innovación paso a producir efectos muy interesantes al envolver al MPE en las actividades y responsabilidad de protección de las personas con sufrimiento mental.

De acuerdo con la Portería 2.391/2002, fue establecido que las internaciones involuntarias deberán ser objeto de notificación las siguientes instancias: 1) Al Ministerio Público Estatal o del Distrito Federal y Territorios donde la situación ocurre. 2) La Comisión Revisora de las internaciones psiquiátricas involuntarias. También establece que la comunicación de IPI, deberá ser hecha en el plazo de 72 horas observando el sigilo de las informaciones, en un formulario propio que deberá contener el laudo medico del especialista perteneciente al cuadro de funcionarios del establecimiento de salud responsable por la internación. En su artículo 8웅.

9 En el embate entre el ciudadano y el Estado, por veces es justificable por razones de seguridad y salud pública, el sacrificio de la autonomía individual. Son los casos de internación compulsoria. (traducción libre de la autora)

${ }^{10}$ La internación voluntaria o involuntaria solamente será autorizada por el médico debidamente registrado en el Consejo Regional de Medicina -CRM - del Estado donde se localice el establecimiento.

$\S 1$ La internación psiquiátrica involuntaria deberá, en el plazo de setenta y dos horas, ser comunicada al Ministerio Publico Estatal por el responsable técnico del establecimiento en el cual ocurrió, debiendo adoptar el mismo procedimiento cuando se dé el alta.

$\S 2$ El termino de la internación involuntaria se da por solicitud escrita de un familiar o responsable legal o cuando es establecido por el especialista responsable del tratamiento. (Traducción libre de la autora) 
Definir que caberá à instituição responsável pela internação involuntária a comunicação da alta hospitalar, conforme modelo de formulário anexo, do qual deverão constar, obrigatoriamente, as seguintes informações: I - numeração da IPI; II - data; III - condições da alta; IV - encaminhamento do paciente ${ }^{11}$.

La Portería 2.391/2002 establece que el gestor estatal de SUS constituirá una Comisión Revisora de las Internaciones Psiquiátricas Involuntarias, con la participación de integrantes designados por el MPE, que llevaran a cabo el seguimiento de esas internaciones, en el plazo de 72 horas después de recibida la comunicación pertinente. De acuerdo con el primer párrafo del articulo 10ํㅣ la comisión deberá ser integrada por multi profesionalmente:

A Comissão deverá ser multiprofissional, sendo integrantes dela, no mínimo, um psiquiatra ou clínico geral com habilitação em Psiquiatria, e um profissional de nível superior da área de saúde mental, não pertencentes ao corpo clínico do estabelecimento onde ocorrer a internação, além de representante do Ministério Público Estadual. É relevante e desejável que dela também façam parte representantes de associações de direitos humanos ou de usuários de serviços de saúde mental e familiares. ${ }^{12}$

Por último, la Portería 2.391/2002 en sus artículos 11,12 y 13 define algunas de las facultades del Ministerio Publico, dentro de las cuales podemos destacar las siguientes: podrá solicitar informaciones complementarias al autor del laudo y a la dirección del establecimiento, también realizar entrevistas con el internado y sus familiares; autorizar a otros especialistas a examinar al internado.

Establecer que la Comisión Revisora efectuara, hasta el séptimo día de la internación y la revisión de cada internación psiquiátrica involuntaria, emitiendo un informe de confirmación o suspensión del régimen de tratamiento adoptado. El director del

\footnotetext{
11 Definir que le corresponderá a la institución responsable por la internación involuntaria la comunicación del alta hospitalaria, conforme al modelo del formulario anexo, del cual deberán constar obligatoriamente los siguientes datos: I- numeración de la IPI, II- fecha, III condiciones de alta; IV tratamiento del paciente.

12 La comisión deberá ser interdisciplinar, siendo integrantes de la misma como mínimo, un psiquiatra o clínico general con habilitación en Psiquiatría, y un profesional de nivel superior del área de salud mental no perteneciente al cuerpo clínico del establecimiento donde se llevaba a cabo la internación, además del representante del Ministerio Publico Estatal. Es relevante y deseable que también formen parte representantes de asociaciones de derechos humanos o usuarios de servicios de salud mental y familiares. (Traducción libre de la autora).
} 
establecimiento enviara, mensualmente, al gestor estatal de SUS una lista que contenga el nombre del paciente internado y el número de notificación de IPI e IPIV.

Según el articulo 9ำ (10.216/2001):

A internação compulsória é determinada, de acordo com a legislação vigente, pelo juiz competente, que levará em conta as condições de segurança do estabelecimento, quanto à salvaguarda do paciente, dos demais internados e funcionários. ${ }^{13}$

De acuerdo con Marchewka (20), a pesar de los avances de la Ley Federal no 10.216/2001, todavía decepciona la internación compulsoria y al portador de trastorno psíquico. Además la Portería Ministerial nำ2391/2002, reglamenta el control de las internaciones psiquiátricas involuntarias y voluntarias, sus procedimientos de notificación de las comunicaciones al MPE. Pero no detalla cómo se sustanciará el procedimiento de fiscalización, ni el control de las internaciones, además de no reglamentar la fiscalización y control de la internación compulsoria. Por eso permanece en el mismo nivel que venían siendo tratadas en la ley ordinaria las cuestiones relacionadas al portador de trastorno mental con conceptualizaciones del siglo XIX.

\section{Conclusión}

En primer lugar es importante destacar que ambos países pasaron por procesos de reformas psiquiátricas que tuvieron como objetivos una mayor protección de los pacientes con padecimiento mental. Proponían entre otras cosas, la extinción progresiva de los manicomios y la sustitución por nuevas modalidades de atención. De ese modo buscaban proteger los Derechos Humanos de los más vulnerables.

Tanto la legislación brasilera como la argentina son posteriores a la Declaración de Caracas, de 1990, que representó un marco muy importante en el desarrollo de la salud mental, en cuyos objetivos se encontraban la superación del modelo del servicio psiquiátrico basado en el hospital psiquiátrico, además de la lucha contra todos los abusos y discriminación de que son víctimas las personas con padecimientos mentales.

13 La internación compulsoria es determina, de acuerdo con la legislación vigente, por el juez competente que tendrá en cuenta las condiciones de seguridad del establecimiento, en cuanto a la protección del paciente, de los demás internados y funcionarios. (Traducción libre de la autora) 
De acuerdo a la legislación de ambos países, observamos que ya sus primeros artículos definen su objeto destacando la protección de los Derechos Humanos de todos los pacientes con padecimientos mentales, teniendo en cuenta la Declaración de los Derechos Humanos, la Declaración de Caraca y los Principios sobre la Protección de las personas con padecimiento Mental de la ONU.

Con respecto a lo dicho podríamos pensar que ambos países tienen políticas públicas para proteger los Derechos Humanos.

En ambos países, la internación involuntaria solo puede darse después de agotar todas las tentativas de utilización de las demás posibilidades terapéuticas, además de todos los recursos extra-hospitalarios disponibles en la red asistencial, realizandose con la menor duración temporal posible. De esta forma constituye, un recurso de última instancia, un recurso de carácter restrictivo.

En la Argentina existen dos clases de internación, la internación voluntaria y la internación involuntaria, en cambio en Brasil existen cuatro clases de internación: internación psiquiátrica involuntaria, internación psiquiátrica voluntaria, internación voluntaria que se transforma en involuntaria y la internación compulsoria. Con respecto a la internación compulsoria, su procedimiento no está regulado. En el caso de la internación involuntaria una vez dada la orden de internación el juez no ejerce ningún control de las mismas. Sera, por lo tanto, el Ministerio Publico Estatal, la comisión revisora y el director del establecimiento donde se de la internación, los que podrán ejercer según la legislación brasilera algún tipo de control. La legislación no detalla cómo se lleva a cabo el proceso de fiscalización.

En el caso de Argentina, en el proceso de control con respecto a las internaciones involuntarias, el juez pedirá informes al equipo médico cada treinta días, con la finalidad de evaluar si persisten las razones para que se mantenga la medida, y podrá requerir en cualquier momento el alta. A los noventa días, después del tercer informe, el juez debe pedir al órgano de revisión que designe un equipo interdisciplinar para obtener una nueva evaluación. Eso significa una mayor seguridad para el paciente. Argentina se encuentra más avanzada en el detalle de la fiscalización de las internaciones con relación a Brasil.

Por último, es noble concluir que a pesar de que ambos países están creciendo en la consolidación de su legislación en salud mental en los últimos años, pero es muy poco el tiempo de su implementación lo que evidencia la falta de avances en el control de los 
procedimientos para asegurar que las políticas publicas realmente protejan los Derechos Humanos.

\section{Bibliografía}

1 - Argentina. Ley 26.657, de 25 de noviembre 2010. Derecho a la Protección de la Salud Mental. Disposiciones complementarias. Derógase la Ley № 22.91. Publicada en el Boletín Oficial, 2010. [Acceso el 8 set 2014]. Disponible en:

http://www.infoleg.gob.ar/infoleglnternet/verNorma.do;jsessionid=F0562C4EADF34073003 $\underline{\text { 8293F7D9BC838?id }=175977}$

2 - Argentina. Decreto 603/2013, de 28 de mayo 2013. Reglamenta Ley 26657. Publicado en el Boletín Oficial. 29 de mayo 2013. [Acceso el 8 set 2014]. Disponible en http://www.infoleg.gob.ar/infoleglnternet/verNorma.do?id=215485

3 - Brasil. Lei 10.216, de 6 de abril de 2001. Dispõe sobre a proteção das pessoas portadoras de transtornos mentais e redireciona o modelo assistencial em saúde mental. Diário Oficial República Federativa do Brasil, Brasília, DF, 6 de abril de 2001. [Acceso el 8 ago 2014]. Disponível em: http://www.planalto.gov.br/ccivil 03/leis/leis 2001/l10216.htm

4 - Brasil. Portaria MS/GM no 2391, de 26 de dezembro 2002. Regulamenta o controle das internações psiquiátricas involuntárias (IPI) e voluntárias (IPV) de acordo com o disposto na Lei no 10.216, de 6 de abril de 2002, e os procedimentos de notificação da Comunicação das IPI e IPV ao Ministério Público pelos estabelecimentos de saúde, integrantes ou não do SUS. Diário Oficial República Federativa do Brasil, Brasília, DF, 26 de dezembro 2002. [Acceso el 28 ago 2014]. Disponível em:

http://dtr2001.saude.gov.br/sas/PORTARIAS/Port2002/Gm/GM-2391.htm

5 - Duarte RP. Uma introdução ao Direito Comparado. O Direito IV. Separata da Revista: 770-782,2006. [Acceso el 25 set 2014]. Disponível em:

http://www.rpdadvogados.pt/pdf/pb/DireitoComparado.pdf.

6 - Sacco R. Introdução ao direito comparado. Tradução de Vera Jacob de Fradera. São Paulo: RT, 2001.

7 - Giovarino MB. El rol de la justicia en las internaciones previstas en la Ley de Salud Mental. Avances de su reglamentación 2013. elDial.com Biblioteca Jurídica, 30 ago. 2013. [Acceso el 20 out. 2014]. Disponible en:

http://www.eldial.com/eldialexpress/home ea nd.asp?Edicion=30/8/2013

8 - Marconi MA, Lakatos EM. Metodologia Cientifica. São Paulo: Atlas; 2007.

9 - Gil CA. Como elaborar projetos de pesquisa. São Paulo: Atlas; 2008.

10 - Severino AJ. Metodologia do Trabalho Científico. São Paulo: Cortez Editora; 2008. 
11 - Serrano PJ. Como utilizar o direito comparado para a Elaboração de Tese Científica. Rio de Janeiro: Forense; 2006.

12 - Levav I, González R. Las raíces de la Declaración de Caracas. In: Rodríguez, Jorge (ed).La reforma de los servicios de salud mental: 15 años después de la Declaración de Caracas. Washington, D.C. OPS, 2007.

13 - Amarante PDC. Saúde Mental, Desinstitucionalização e Novas Estratégias de Cuidado. In: Giovanella $L$ et al, organizadores. Políticas e sistemas de saúde no Brasil. Rio de Janeiro: Fiocruz; 2008.

14 - Maciel SC. Reforma psiquiátrica no Brasil: algumas reflexões. Cadernos Brasileiros de Saúde Mental.2012 [Acceso el 10 out 2014]. 4(8): 73-82. Disponível em: http://incubadora.periodicos.ufsc.br/index.php/cbsm/article/view/2021/2307

15 - Ottaviano ML. La Institución Psiquiátrica y el proceso de reforma en el campo de la Salud Mental. Revista Electrónica de Psicología Política. 2011 [Acceso el 9 set 2014]. 9(26):44-52. Disponible en: http://www.psicopol.unsl.edu.ar/agosto11 nota3.pdf

16 - Organização Mundial Da Saúde. Plan de acción sobre Salud Mental 2013-2020. Genebra: Organização Mundial da Saúde, 2013. [Acceso el 2 out 2014]. Disponível em: http://apps.who.int/iris/bitstream/10665/97488/1/9789243506029 spa.pdf

17 - Sainz GA et al. Ley Nacional de Salud Mental №26.657: comentarios interdisciplinarios. elDial.com Biblioteca Jurídica. 2012. [Acceso el 20 oct 2014]. Disponible en: http://www.eldial.com.ar/nuevo/archivo-doctrina nuevo.asp?base $=50 \& i d=6532 \& \mathrm{t}=\mathrm{d}$

18 - Escudero BQ. Consideraciones sobre el Decreto 603/13, regulamentário de la Ley de Salud Mental. elDial.com Biblioteca Jurídica, 29 jul. 2013. [Acceso el 20 ouc 2014].

Disponible en: http://www.eldial.com/nuevo/archivodoctrina nuevo.asp?base $=50 \& \mathrm{t}=\mathrm{d} \& \mathrm{id}=6956$

19 - De Lima TMM, De Sá MFF. Autonomia privada e internação não consentida. Revista Brasileira de Estudos Políticos, 2009. 99:79-99.

20 - Marchewka TMN. Saúde mental no contexto do Direito Sanitário. In: Costa AB et al (orgs). O Direito achado na rua: introdução crítica ao Direito a Saúde. Brasília: CEAD/UnB, 2009. 207-209p. 